1

2

3

4

5

6

7

8

9

10

11

12

13

14

15

16

17 Corresponding author:

18 Ross Murray, $\mathrm{PhD}$,

19 University of Stirling,

20 FK9 4LA

$21 \quad \mathrm{~T}:$ +44 7522727369

22 E: rmm6@stir.ac.uk

23 Accepted refereed manuscript of:

Murray RM, Coffee P, Eklund RC \& Arthur CA (2019) Attributional consensus: The importance of agreement over causes for team performance to interpersonal outcomes and performance. Psychology of Sport and Exercise, 43, pp. 219-225.

DOI: https://doi.org/10.1016/j.psychsport.2019.03.001

(C) 2019, Elsevier. Licensed under the Creative Commons Attribution-NonCommercial-NoDerivatives 4.0 International

http://creativecommons.org/licenses/by-nc-nd/4.0/ 
Abstract

Objectives: Investigate (a) the effects of attributional consensus on interpersonal outcomes and performance, (b) the effects of attribution type (i.e., adaptive/maladaptive) on performance, and (c) the interactive effects between attributional consensus and attribution type on performance. Design: Across two studies (i.e., vignette and behavioural experiments), independent samples ttests were used to examine the main effects of attributional consensus on interpersonal outcomes. A 2 (attributional consensus: high, low) x 2 (attribution type: adaptive, maladaptive) x 2 (time: pre, post) ANOVA with repeated measures on the last factor was used to analyse the main and interaction effects of attributional consensus and attribution type on performance.

Method: In Study 1, participants $(N=100)$ read a vignette describing a hypothetical situation in which they and their partner agreed or disagreed over an adaptive or maladaptive attribution. They then completed measures of conflict and cohesion. In Study 2, participants $(N=56)$ completed an experiment in which they performed a dart throwing task with a partner (a confederate) and were subsequently told they failed the task. After selecting an adaptive or maladaptive attribution, the confederate then agreed or disagreed with the participant. Measures of conflict, cohesion, social identity, and performance were then taken.

Results: High attributional consensus led to lower levels of conflict and higher levels of cohesion and social identity. Further, regardless of attribution type, high attributional consensus led to better performance.

Conclusion: Overall the results provide evidence for the positive effects of high attributional consensus on interpersonal and performance outcomes. Keywords: Team-referent attributions, Disagree, Adaptive, Maladaptive 
Attributional Consensus: The Importance of Agreement over Causes for Team Performance to Interpersonal Outcomes and Performance team/group outcomes occurred (Allen, Coffee, \& Greenlees, 2012). Researchers studying attributions have observed associations between team-referent attributions and sport outcomes

51 (Allen, Jones, \& Sheffield, 2009; Coffee, Greenlees, \& Allen, 2015; Dithurbide, Sullivan, \&

52 Chow, 2009). Specifically, through experimental designs, researchers have observed the causal

53 effects of attributions on cognitive, affective, and behavioural outcomes (Le Foll, Rascle, \&

54 Higgins, 2008; Rascle et al., 2015; Rees et al., 2013) and these effects are believed to be

55 generalizable at the team level (Allen et al., 2012). However, within a team setting, the presence

56 of teammates' attributions might impact these relationships. In accordance with attribution

57 theory (Kelley, 1967), this might be because individuals seek consensus information during the

58 attribution process. That is, by seeking consensus information, people aim to comprehend others'

59 attributions to understand if they explained the same outcome in the same way. Therefore, while

60 attribution studies have provided a good understanding of the effects of attributions, researchers

61 have not accounted for the influence that teammates can have on the attribution process. The

62 current study was designed to examine the effect of teammates agreeing or disagreeing over

63 team-referent attributions (i.e., attributional consensus) on the attribution process. Attributional

64 consensus between teammates likely lies on a continuum between complete agreement to

65 complete disagreement; this study was designed to examine the interpersonal and behavioural 66 consequences of teammates diverging along this continuum and finding themselves at opposite

67 ends of this attributional consensus spectrum.

\section{Attributional Consensus}


Individuals working collectively to achieve a common goal, as is the case in sport teams, are likely to agree and disagree on issues pertinent to collective performances (Jehn \& Mannix,

71

72 2001). According to the actor-observer bias/asymmetry, actors (individuals) have a propensity to attribute their own behaviour to situational characteristics, while observers (others) tend to explain the same behaviour through an actor's personal disposition (Jones \& Nisbett, 1971). The concept underpinning this is that attributions are a product of personal perspectives, and these perspectives can vary between individuals. For example, an athlete might believe his team lost due to a poor effort, while a teammate could believe the same loss was due to a lack of ability. These diverging perspectives exemplify how individuals within a team may derive different causes to explain a collective performance (i.e., low attributional consensus). Consequently, disagreement is an inevitable part of group involvement.

Low attributional consensus between group members can lead to negative outcomes such as intra-group conflict (Mitchell, 2018). Although disagreement and conflict may often be perceived as synonymous with one other, researchers in social and sport psychology suggest that disagreement between team members is a precursor to intra-team conflict (Barki \& Hartwick, 2004; Paradis, Carron, \& Martin, 2014). Among sport teams, disagreement that leads to conflict is generally perceived to be negative, as conflict is often associated with negative group outcomes such as experiences of negative emotions and disruption of collective goals (Barki \& Hartwick, 2004). Disagreement between team members, however, can also be perceived as a healthy and a potentially important aspect of team dynamics (Goncalo \& Duguid, 2008). Thus, the extent to which disagreement in the form of low attributional consensus causes conflict among teammates warrants examination.

On the other hand, agreement between team members during the attribution process (i.e., 
92 high attributional consensus) may facilitate positive intra-group effects. For example, in coach-

93 athlete dyads, those who tend to agree more often report greater feelings of trust and friendship

94 with one another (Jackson, Dimmock, Gucciardi, \& Grove, 2011), and these relationships are

95 indicative of cohesive teams (Mach, Dolan, \& Tzafrir, 2010). Researchers have demonstrated a

96 positive association between agreement within teams and perceived cohesion (Carron et al.,

97 2003). Thus, team members who believe their team is cohesive, may perceive this cohesion to be

98 a product of agreement over important team processes such as team-referent attributions. This

99 relationship is akin to the process of consensualisation regarding social identity. The process of

100 consensualisation can occur when individuals who agree with one another are more likely to feel

101 a stronger sense of shared identity (Postmes, Haslam, \& Swaab, 2005). That is, the process of

102 agreement facilitates a stronger sense of attachment to the group among individuals, and in turn

103 they define themselves from their connection with their group (Tajfel, 1982). In short,

104 individuals tend to feel more cohesive and share a social identity with others who agree with 105 them.

This is likely a reciprocal relationship as social identity often influences the decision-

107 making process within teams (Postmes et al., 2005). Therefore, the effect of agreement or

108 disagreement over attributions on social identity and cohesion is difficult to empirically examine

109 as agreement is likely influenced by existing levels of social identity and cohesion. As a starting

110 point, the current research is designed to examine these relationships in newly formed groups,

111 thereby, restricting the possibility of existing levels of social identity and cohesion impacting the

112 effect of attributional consensus on outcomes.

\section{Attribution Dimensions}

114 Traditionally, attributions are examined at the dimensional level (Rees, Ingledew, \& 
115 Hardy, 2005; Weiner, 1985). This means, when measuring attributions, the way in which

116

117

118

119

120

121

122

123

124

125

126

127

128

129

130

131

132

133

134

135

136

137

individuals appraise their attributions is of importance. For example, an individual who attributes

an unsuccessful performance to a lack of ability may believe this cause is something that is

uncontrollable and unlikely to change in the future (stable). However, this same attribution could

also be believed to be something that can be controlled through practice, and therefore can

change in the future (unstable). Through this dimensional structure, Rees and colleagues theorize that attributions can be assessed on perceptions of controllability (the extent to which a cause is

perceived as controllable or uncontrollable), stability (the extent to which a cause is perceived as stable or variable over time), globality (the extent to which a cause is perceived to affect a wide or narrow range of situations), and universality (the extent to which a cause is perceived as common or unique to all people/teams).

Generally, athletes who attribute an unsuccessful performance to causes that are controllable and likely to change in the future are said to have adaptive attributions (controllable and unstable), while those who attribute an unsuccessful performance to causes that are uncontrollable and unlikely to change in the future are said to have maladaptive attributions (Rees et al., 2005). The type of attribution (i.e., adaptive or maladaptive) an individual adopts is believed to impact important sport outcomes (Rees et al., 2005). Those who adopt, when possible, adaptive attributions are more likely to persist in a challenging task (Le Foll et al., 2008; Rascle et al., 2015), be more confident (Coffee et al., 2015; Coffee \& Rees, 2009), and ultimately perform better in a subsequent sport performance task (Rees et al., 2013). However, minimal research exists that has examined the influence teammates have on these attributionoutcome relationships.

\section{Attributional Consensus and Performance}


Teammates may have a strong influence on the attributional process. For example, in work groups, disagreement between teammates impaired group performance (van Woerkom \& Sanders, 2010), which in turn had deleterious effects on individual performance. In terms of attributions in sport, the effects of disagreement with teammates may be dependent on the content of the athlete's attribution. For example, confirmation bias suggests that individuals will seek out information that supports their existing belief (Jonas, Schulz-Hardt, Frey, \& Thelen, 2001). Therefore, a teammate agreeing with an adaptive or maladaptive attribution should reaffirm an individual's belief, increasing or decreasing performance respectively.

\section{Current Studies}

Within this paper, two studies are detailed that were designed to examine the effect of attributional consensus between teammates. To do this, an approach similar to that of previous attribution studies (Le Foll et al., 2008; Rascle et al., 2015) was adopted, in that attributions after failure were analysed on a spectrum from adaptive (i.e., controllable and unstable) to maladaptive (i.e., uncontrollable and stable). High attributional consensus was operationalised as convergence on one end of the spectrum (i.e., adaptive-adaptive, maladaptive-maladaptive) while low attributional consensus was operationalised as a divergence toward opposite ends of the spectrum (i.e., adaptive-maladaptive, maladaptive-adaptive). This approach was adopted to explore if high or low attributional consensus influenced perceptions of interpersonal outcomes and objective performance.

Although an attribution dimensional approach was adopted, unlike previous attribution experiments (Le Foll et al., 2008; Rascle et al., 2015), the main purpose of these studies was to explore the effects of attributional consensus on interpersonal outcomes. As such, whether participants adopted an adaptive or maladaptive attribution was not expected to impact the 
161 interpersonal relationship with their teammate. In other words, adaptive and maladaptive

162 attributions were used as a mechanism to facilitate unambiguous agreement or disagreement

163 between the participant and the confederate. Therefore, no specific hypotheses regarding the

164 effect of adaptive and maladaptive attributions on interpersonal outcomes were tested. However,

165 because researchers have demonstrated the effect of adaptive/maladaptive attributions on

166 subsequent performance (Rees et al., 2013), the effect of these conditions on performance were

167 tested.

Dyadic teams were used to investigate the effect of attributional consensus and attribution

169

170

171

172

173

174 175 outcome.

176

177

178

179

180

181

182

183

\section{Method}

type on interpersonal outcomes and performance. Moreland (2010) argues that individuals'

experiences in dyads are conceptually different from individuals' experiences in groups. This is

to some extent true, yet Williams (2010) argues that, in most cases, dyads are groups as they

share the same principles and processes of larger groups. Within the current studies, dyads were

considered to be groups as, consistent with William's argument, the dyads engaged in behaviours

and processes that paralleled that of larger groups. That is, dyads worked to achieve a collective

In Study 1 a vignette design was used to explore the possible effects of attributional consensus on relational outcomes of conflict and cohesion. Specifically, it was predicted that those in the low attributional consensus condition would report more conflict and less cohesion than those in the high attributional consensus condition (Hypothesis 1a).

\section{Study 1}

Participants and design. Based on Coffee, Rees, and Haslam (2009), who used a vignette study to analyse the effects of attributions, a moderate effect size was used to calculate 
184 185

power. Power calculations revealed a $95 \%$ chance of detecting a moderate effect $d=.65$, with a sample of 104 individuals.

After three individuals were removed for failing the screening questions, a final online sample of 56 men and 44 women tennis players was used $\left(N=100, M_{\text {age }}=21.56, S D=5.12\right)$. Tennis players were sampled as tennis is often played in a doubles format. The study adopted a 2 (attributional consensus: low, high) x 2 (attribution type: adaptive, maladaptive) factor design. Participants were recruited through tennis clubs' web pages. To ensure participants played tennis and they could fully and vividly imagine the situation after exposure to the vignette, they were asked two screening questions: 1) “At what level do you play tennis?" and 2) "How well were you able to imagine the scenario?" As previously mentioned, three individuals failed the screening questions by answering not at all for either one or both questions and were subsequently removed from the analysis. The remaining 100 individuals (25 per condition) competed at various levels (recreational: $n=21$, club: $n=56$, national: $n=19$, international: $n=$ 4) and could moderately $(n=70)$ or vividly $(n=30)$ imagine the scenario.

Procedure. Approval for the study was granted through a university's research ethics board. Those agreeing to participate in the study clicked a link taking them to an informed consent page. Once participants provided consent, they were asked to complete brief demographic items assessing participants' gender and age. They then read the following vignette:

You are competing in a tennis doubles competition with a partner of similar ability who you have never met. In this competition, you and your partner (the team) perform very poorly and fail.

Half of participants then read a situation in which they and their partner disagreed on an adaptive 
207 [or maladaptive] attribution.

You think the main reason the team failed is due to a poor strategy [the difficulty of the task]. This is something that the team can[not] control and something that does [not] change over time. However, your partner disagrees with you and thinks the main reason the team failed is due to the difficulty of the task [a poor strategy]. This is something that the team cannot [can] control and something that does not [does] change over time.

The other half of participants read a situation in which they and their partner agreed on an adaptive [or maladaptive] attribution.

You and your partner agree that the main reason the team failed is due to a poor strategy [the difficulty of the task]. This is something that the team can[not] control and something that does [not] change over time.

Participants then completed items measuring perceptions of conflict and cohesion.

Measures. Single item measures were used to assess perceptions of conflict and cohesion. Due to the exploratory nature of this vignette study, and the use of single item measures in previous social psychology studies (Postmes, Haslam, \& Jans, 2013), these items were deemed to be appropriate. Participants were asked to rate the extent they believed they and their partner would likely experience conflict and cohesion. These were rated on a scale from 1 (not at all) to 5 (completely).

\section{Results}

Independent samples $t$-tests were used to analyse how agreeing (i.e., high consensus) or disagreeing (i.e., low consensus) on attributions affected perceptions of conflict and cohesion. There were no obvious violations of assumptions as dependent variables appeared normally 
distributed and Levene's test for equality of variances was not significant, $p \mathrm{~s}>.38$.

Conflict. Those in the low attributional consensus condition reported significantly greater levels of conflict, $M=2.92, S D=1.01$, compared to those in the high attributional consensus condition, $M=2.38, S D=.83, t 98=2.93, p=.004, d=.59$.

Cohesion. Those in the low attributional consensus condition reported significantly lower levels of cohesion, $M=2.70, S D=.95$, compared to those in the high attributional consensus condition, $M=3.12, S D=.94, t_{98}=2.22, p=.029, d=.45$.

\section{Study 1 Discussion}

These results provide initial support for the effects of attributional consensus on interpersonal outcomes. Specifically, these results are consistent with previous research (e.g., Barki \& Hartwick, 2004; Pescosolido \& Saavedra, 2012) as disagreement appears to be associated with interpersonal conflict and agreement appears to be associated with perceptions of cohesion. However, the generalisability of the results are limited. First, the study only targeted tennis players. This may raise questions regarding the effects of attributional consensus in other settings. Second, the study examined how participants' perceptions of interpersonal outcomes are influenced by a hypothetical situation. Such a design does not provide a good setting to examine behavioural outcomes like performance or outcomes that emerge through behavioural interaction like social identity. Therefore, the purpose of Study 2 was two-fold. First, Study 2 was designed to replicate the effects found in Study 1 through a controlled behavioural experiment. Second, Study 2 was designed to build on Study 1 by examining the main effects of attributional consensus on social identity, as well as the main and interactive effects of attributional consensus and attribution type on objective performance.

In Study 2 it was predicted that those in the low attributional consensus condition would 
253 report weaker social identity and perform worse compared to those in the high attributional 254 consensus condition (Hypothesis 1b). Further, it was predicted that participants who adopted an 255 adaptive attribution would perform better compared to those who adopted a maladaptive 256 attribution (Hypothesis 2). Finally, an interaction effect between adaptive/maladaptive 257 attributions and attributional consensus was predicted (Hypothesis 3). Specifically, it was

258 predicted that participants would perform better when their teammate agreed with their adaptive 259 attribution compared to when their teammate agreed with their maladaptive attribution or 260 disagreed with their adaptive or maladaptive attribution.

\section{Study 2}

\section{Method}

Participants. Rascle et al. (2015) and Rees et al. (2013) observed large effect sizes when examining the effects of attributions on behaviour. Power calculations revealed that to detect a

265 large effect size $\left(\eta_{\mathrm{p}}^{2}=.30\right)$, a sample of 52 individuals was needed. Two participants did not complete the study as they failed a manipulation check. This left a final sample of 24 men and 32

267 women who were students at a university in the UK $\left(N=56, M_{\text {age }}=23.86, S D=6.42\right)$. On a scale from 1 (no experience) to 10 (a lot of experience) participants reported little dart throwing experience $(M=2.62, S D=1.91)$.

Materials. A regulation size dart board was mounted 1.73 meters from the bull's-eye to

271 the ground (the regulation dart throwing height) and participants threw from 2.37 meters (the 272 regulation dart throwing distance). This distance was marked out by a line on the floor. These 273 materials and distances are consistent with the materials and distances used in Rascle et al.

274 (2015). During each performance, a visual shield was in place to ensure the non-performer was 275 not able to see their teammate's score. 


\section{Measures.}

Conflict and cohesion. The measures of conflict and cohesion used in Study 1 were also used in Study 2.

Social identity. To examine the effect of attributional consensus on social identity, participants completed the Single Item Social Identity Scale (SISI) (Postmes et al., 2013). The SISI asks participants to report the extent to which they agree with the statement "I identify with [target group]" on a 7-point scale ranging from 1 (completely disagree) to 7 (completely agree). In this study, "target group" was replaced with "my team".

Performance. To measure performance, participants completed two rounds of a dart throwing task (pre-manipulation and post-manipulation). The dart board was divided into 10 sections in concentric circles ranging from 1 (around the outside) to 10 (bull's-eye), with higher scores corresponding to a better performance. Each round participants threw six darts. Higher scores corresponded with those who threw their darts closer to the middle of the dartboard. Participants who missed the dartboard completely were given a score of zero for that throw.

Manipulation checks. To ensure participants perceived their performance as a failure and understood the manipulation, they were asked to circle a) whether their performance was "rather like a success" or "rather like a failure" and b) which paragraph they selected and which paragraph their teammate (the confederate) selected. After the experiment participants were asked whether they were aware of the true purpose of the study.

Procedure. Ethical approval for the study was granted by a university's research ethics board. A participant and the confederate entered the laboratory and were provided details regarding the nature of the study. They then completed an informed consent form and were notified that they would be completing a dart throwing task together as part of a team. They were 
given a collective target score of 90 with 12 darts and were informed that they would each throw six darts ${ }^{1}$. Once the participant and confederate indicated they understood the task, the researcher informed them that the participant would perform first. The researcher then instructed the confederate to stand behind a visual shield so the teammate's performance was visible but the score (dartboard) was not visible. After the participant threw six darts and the scores were recorded and the darts removed, the participant and confederate switched positions and the confederate threw six darts. Subsequently, the researcher informed them that, as a team, they did not reach the target score of 90 and thus had failed the task.

Participants were then asked to read two paragraphs describing (1) an adaptive attribution and (2) a maladaptive attribution (e.g., Rascle et al., 2015) and asked to circle the paragraph they believed best described the causes of their team performance. The researcher then prompted participants to verbally state which attribution they selected. This self-selection procedure was reinforced as the researcher reminded them that they chose an attribution that was [un]controllable and [un]likely to change. To manipulate attributional consensus, when asked, the confederate verbally agreed and stated the selection of the same attribution (high attributional consensus, $n=26$ ), or disagreed and stated the selection of the other attribution (low attributional consensus, $n=26$ ). To help ensure equal group sizes, a quasi-random allocation method was used as participants were assigned to either the low attributional consensus condition or high attributional consensus condition by the researcher before the trial. Following the attributional consensus manipulation, participants were asked to complete the manipulation check and measures of conflict, cohesion, and social identity. They then completed the task for a second and final time. After the second and final performance, participants were informed that the study

${ }^{1}$ Pilot testing indicated that, given the option of an adaptive or maladaptive attribution, around half of participants would circle an adaptive attribution after failing to reach a target score of 90 . 
was complete and were fully debriefed.

Analyses. Akin to Study 1, the effects of attributional consensus on conflict, cohesion, and social identity were analysed using $t$-tests. To analyse the main and interactive effects of attribution type and attribution consensus on performance, a 2 (attribution type: adaptive, maladaptive) x 2 (attribution consensus: high, low) x 2 (time: pre, post) ANOVA with repeated measures on the last factor was used.

\section{Results}

Descriptive statistics and bivariate correlations for Study 2 variables are detailed in Table 1. A visual inspection revealed no violations of normality for the cohesion, social identity or performance variables; however, a positive skew indicating floor effects for the conflict variable was observed. Parametric tests were applied as researchers have demonstrated the robustness of independent samples t-tests using small sample sizes with floor effects (Sullivan \& Agostino, 1992). Equal variances were assumed for social identity but not assumed for conflict and cohesion; therefore, the Satterthwaite (1946) adjustment was applied for analyses on conflict and cohesion. For the performance variables, there were no significant differences in error variances across groups, $p \mathrm{~s}>.54$.

Manipulation checks. Two participants circled "rather like a success" and were subsequently removed from the study. All 56 participants who completed the study correctly identified the attribution they selected and the attribution the confederate selected. Further, no participants indicated they were aware of the true purpose of the study.

\section{Demographic variables.}

Age and experience. A 2 (attribution type: adaptive, maladaptive) x 2 (attribution consensus: high, low) ANOVA revealed no significant differences in age or experience between 
344

345

346

347

348

349

350

351

352

353

354

355

356

357

358

359

360

361

362

363

364

365

366

attribution type conditions and attributional consensus conditions ( $p$ s > .37).

Gender. $T$-tests indicated that men, $M=3.12, S D=.80$, reported higher levels of cohesion than women, $M=2.56, S D=1.01, t_{54}=2.32, p=.024$. There were no gender differences for conflict and social identity. Further, a 2 (gender: men, women) x 2 (time: pre, post) ANOVA with repeated measures on the last factor revealed no main or interaction effects for gender $(p s>.14)$.

Conflict. Akin to Study 1, there was a significant effect of attributional consensus on perceptions of conflict. Generally, participants reported higher levels of conflict when their teammate (the confederate) disagreed and selected the other attribution, $M=1.89, S D=.99$, compared to conditions in which the confederate agreed with the participant, $M=1.28, S D=.53$, $\mathrm{t}_{54}=2.85, p=.007, d=.88$.

Cohesion. There was also a significant effect of attributional consensus on perceptions of cohesion. Participants in conditions of high attributional consensus, in general, reported more cohesion, $M=3.07, S D=.57$, than participants in conditions of low attributional consensus, $M=$ $2.54, S D=.54, \mathrm{t}_{54}=2.15, p=.038, d=.69$.

Social identity. A significant effect of attributional consensus on social identity was also observed. Participants in high attributional consensus conditions generally reported higher levels of social identity, $M=4.37, S D=.1 .34$, compared to those in low attributional consensus conditions, $M=3.43, S D=1.10, \mathrm{t}_{54}=2.83, p=.006, d=.77$.

Performance. A 2 (attribution type: adaptive, maladaptive) x 2 (attribution consensus: high, low) ANOVA revealed no significant differences in pre-manipulation scores between conditions $(p s>.35)$. A 2 (attribution type: adaptive, maladaptive) x 2 (attribution consensus: high, low) x 2 (time: pre, post) ANOVA with repeated measures on the last factor revealed an 
367 interaction between attribution consensus and time, $F_{1,52}=4.49, p=.039, \eta_{\mathrm{p}}^{2}=.08$. Compared 368 to pre-manipulation baselines, participants in high attributional consensus conditions performed 369 significantly better post-manipulation $(p=.018)$. There was no evidence of an effect between 370 attribution type and time on performance, $F_{1,52}=.30, p=.58, \eta_{\mathrm{p}}^{2}=.01$ and there was no 371 interaction effect between attribution type and attributional consensus across time, $F_{1,52}=.13, p$ $372=.72, \eta_{\mathrm{p}}^{2}=.003$

Evidence supporting the effect of attributional consensus on conflict and cohesion in real 375 groups was observed in Study 2. Generally, when the confederate disagreed rather than agreed 376 with participants' attributions, participants reported more conflict, less cohesion, and lower 377 levels social identity with the confederate. Finally, consistent with previous findings (De Dreu \& 378 Weingart, 2003), the effect of agreement between the confederate and participants appeared associated with improved participant performance. Importantly, this finding was observed regardless of adaptive or maladaptive attributions.

\section{General Discussion}

383 affects interpersonal outcomes and performance (Hypotheses 1a and b), if attribution type (i.e., 384 adaptive or maladaptive) affects performance (Hypothesis 2), and if attribution type and 385 attributional consensus interact to affect performance (Hypothesis 3). Across the two studies and 386 in line with Hypotheses 1a and 1b, high attributional consensus between teammates generally led 387 to perceptions of less conflict, more cohesion, stronger social identity, and better performance 388 compared to low attributional consensus between teammates. Hypotheses 2 and 3 were not supported as, contrary to previous attribution studies, attribution type did not affect performance, 
and there was no interaction between attributional consensus and attribution type. Instead, evidence that attributional consensus between teammates might influence performance was observed. In other words, agreement over the cause of an unsuccessful performance appeared more influential to subsequent performance than the content of the attribution. Overall, the results provide evidence for the effects of attributional consensus on interpersonal outcomes and performance.

Attributional consensus appeared to influence interpersonal outcomes, including conflict, cohesion, and social identity. Those in the low, compared to the high, attributional consensus condition reported greater conflict. While some individuals and teams may handle conflict well, in general, experiences of conflict are often accompanied with experiences of negative emotions and perceived disruption of future goals (Barki \& Hartwick, 2004). Similarly, compared to high attributional consensus, those who experienced low attributional consensus reported lower levels of cohesion. Cohesion among team members is known to be beneficial at the team and individual level (Carron, Colman, Wheeler, \& Stevens, 2002). Thus, generally, the results from these studies indicate that attributional consensus might be an antecedent to important group dynamics that can influence team functioning.

Those in the high attributional consensus condition also typically reported stronger perceptions of social identity compared to those in the low attributional consensus condition. Because participants had no prior relationship with the confederate, the process of agreeing on attributions may have contributed to the development of social identity (Swaab, Postmes, Neijens, Kiers, \& Dumay, 2002). In other words, through the interaction between the group members (the attributional consensus manipulation), participants' agreement or disagreement with the confederate could have influenced levels of shared social identity. This can be explained 
413 through the process of consensualisation (Postmes et al., 2005). According to Postmes and 414 colleagues, consensualisation occurs when agreement with group members builds social identity.

415 This might explain why participants reported higher levels of social identity when the 416 confederate agreed with them, compared to when the confederate disagreed with them.

A particularly novel finding is that, when it comes to performance, it appears that agreeing with team-members may be of more importance than the type of attribution. Although attribution researchers have previously demonstrated that performance improves when adaptive,

420 compared to maladaptive, attributions are adopted (Rees et al., 2013), the results of Study 2

421 indicate that attribution type had no effect on performance. The process of attributional

422 consensus may provide insight into this finding. Specifically, agreeing or disagreeing on

423 attributions may have reduced or negated the effects of adopting an adaptive or maladaptive

424 attribution. In other words, in a team setting, the process of agreeing or disagreeing on

425 explanations for performance might be of high importance.

427 Central to Balance Theory is the idea that one seeks harmony between themselves and the

428 situation or surrounding environment. Therefore, when a dyad experiences low attributional

429 consensus, there is a perceived imbalance. For example, when an individual learns that her

430 partner has a different attribution for a poor collective outcome, she perceives an imbalance. This

431 imbalance can then cause stress within the team members and lead to a poorer performance.

432 Indeed, Balance Theory has been used to explain negative performance effects on team motor

433 tasks (Boss \& Kleinert, 2015). This may explain why participants whose team agreed on an

434 adaptive cause did not typically perform better than participants whose team agreed on a

435 maladaptive cause. In both conditions, participants may have perceived a balance between 
themselves, their partner, and their collective performance. However, under conditions of disagreement, they may have perceived an imbalance, perhaps causing stress, which resulted in poorer subsequent performance.

No interaction effect between attributional consensus and attribution type was observed. As expected, when the confederate disagreed with participants' adaptive attributions, they generally reacted negatively. However, when the confederate disagreed, and communicated a more adaptive attribution that contrasted participants' maladaptive attributions, participants typically did not perform better. While researchers have demonstrated that adaptive attributions from an in-group member can be a source of motivation (Rees et al., 2013), this did not appear to be the case in the current study. This might be because the effect of disagreement between teammates superseded the effect of attribution type. For example, participants may have been less motivated by an adaptive attribution upon learning their teammate disagreed with them. Of course, in more naturalistic conditions, teammates would be able to communicate further and perhaps come to an understanding. Indeed, in field studies adaptive team-referent attributions have been linked to successful performance (Carron, Shapcott, \& Martin, 2014). Thus, moving beyond the scope of this research, these effects might change dependent on whether teammates have the opportunity to resolve the disagreement.

\section{Strengths and limitations}

Traditionally, in attribution studies, participants are told they have an adaptive or maladaptive attribution (Le Foll et al., 2008; Rascle et al., 2015; Rees et al., 2013). This approach has demonstrated the differential effects of adaptive and maladaptive attributions on behavioral outcomes; however, the process in which attributions are communicated from researcher to participant is inconsistent with the actual attribution process an athlete experiences. 
459 In more natural settings, it is likely athletes develop their own attributions for performance, and 460 these may then be influenced by those around them. Therefore, a key strength of Study 2 was 461 that it permitted individuals to choose their attribution, thus more closely resembling the actual 462 attribution process. A caveat to this, however, is that participants were not subsequently able to 463 change their attribution after input from their teammate. Regardless, participants' attributions did 464 not appear to influence their performance and, as such, these results diverge from previous 465 attribution research (Rees et al., 2013). Building on the results of the current study, researchers 466 should explore whether athletes change their attributions after input from their teammates and 467 the extent to which this process can be generalized to more natural settings.

While the results of Study 2 highlight how social identity may be built through the 469 process of agreeing with group members, under non-experimental conditions existing levels of 470 social identity likely influence the propensity for agreement and the effects of agreement 471 (Postmes et al., 2005). In other words, there is likely a reciprocal relationship between 472 attributional consensus and social identity. While the current studies were limited to testing only 473 one direction of this relationship, it is likely that levels of social identity may also impact the 474 extent to which individuals experience attributional consensus.

Another limitation resulting from the experimental conditions concerns the extent to 476 which results are meaningful to larger intact teams. The research was completed in dyads in a 477 highly contrived situation where the interaction between the ostensible teammates was brief.

478 While this does not preclude the measurement of pertinent group processes (e.g., Tajfel, 1970), it 479 is unknown the extent to which the differences observed would disrupt or enhance psychological 480 processes in intact teams. For example, although there were significant differences between the 481 high and low consensus conditions in terms of conflict between two individuals, under non- 
482 483 484 485 486 487 488 489 490 491 492 493 494 495 496 497 498 499 500 501 502 503 504

experimental conditions it is unknown whether larger intact teams would benefit from the lower levels of conflict and higher levels of cohesion and social identity reported in the low attributional consensus condition.

Finally, there are a number of methodological limitations that should be addressed. The adoption of full random allocation and double-blinding in the behavioural experiment would have limited the possibility of subjective bias. Another methodological limitation was that, unvalidated single-item measures were used to measure levels of conflict and cohesion. Lastly, regarding the effect of attribution consensus on performance, a large effect size was anticipated yet a small effect size was observed. Therefore, researchers aiming to replicate these findings would likely need to use a larger sample size than the one obtained within this study.

\section{Future research}

The aforementioned limitations should be addressed in subsequent independent replication studies. Alongside replication studies, researchers might consider building upon these findings by examining the situations in which might not lead to higher levels of conflict (Jehn, 1995). Indeed, under certain conditions, agreement may have negative effects while disagreement may be advantageous. For example, agreement between team members (i.e., high consensus) can foster atmospheres in which groupthink is prevalent (Hart, 1991), while sharing different information among teammates (i.e., low consensus) can be beneficial to performance (Goncalo \& Duguid, 2008). As such, there may be times when teams will benefit from low attributional consensus. If coaches and teammates observed different reasons for their team's unsuccessful performance, it may be in the team's best interest to hear all potential explanations to maximise their chances of amending mistakes. As such, an avenue for future research might be to investigate the conditions under which low attributional consensus can facilitate 
505 performance without leading to negative consequences.

Both conflict and cohesion were measured as unidimensional constructs, however, they

507 are often measured as multidimensional constructs (Carron, Widmeyer, \& Brawley, 1985; De

508 Dreu \& Weingart, 2003). Therefore, researchers could examine the effect of attribution

509 consensus on the multidimensional aspects of conflict and cohesion. That is, the constructs are

510 typically categorized into task and social conflict and task and social cohesion. As such,

511 researchers may want to examine how attributional consensus impacts perceptions of task and

512 social aspects separately. For example, because attributional consensus relates directly to

513 individuals' perceptions of a task, it is possible the detrimental effects experienced pertain more

514 to perceptions of task conflict and cohesion compared to social conflict and cohesion.

\section{Implications}

516 Assuming these results can be replicated in subsequent research, they might have practical value

517 for intact teams. Typically, maladaptive attributions were considered to be uniformly negative.

518 However, the results of the current study suggest that consensus over maladaptive attributions

519 might be beneficial. For example, when a team explains a poor performance as due to the

520 weather - something that cannot be controlled - consensus among team members that the cause

521 of their poor performance was due to the weather may actually be beneficial, even though the

522 attribution is maladaptive. In other words, teammates agreeing on the cause of events - being on

523 the same page, so to speak — may be important even if it is agreeing that we cannot control the

524 cause of a negative outcome.

525 Conclusion

526 The results of these studies provide valuable insight into the processes teams experience

527 after failure. Specifically, these results indicate that teams may benefit from agreement over the 
528 cause of an unsuccessful performance. Direct replications are needed to confirm study findings

529 and understand how low attributional consensus within a team might cause conflict and

530 reductions in cohesion and social identity, and how low attributional consensus may be a cause

531 of poor performance. It is important how athletes individually attribute failure (Rees et al.,

532 2013); however, in a team setting, whether teammates perceive the same cause for failure may be

533 of greater significance. 


\section{Formatting of funding sources}

535 This research did not receive any specific grant from funding agencies in the public, commercial, 536 or not-for-profit sectors.

537 Declarations of interest: none 


\section{References}

Allen, M. S., Coffee, P., \& Greenlees, I. (2012). A theoretical framework and research agenda for studying team attributions in sport. International Review of Sport and Exercise Psychology, 5(2), 121-144. http://doi.org/10.1080/1750984X.2012.663400

Allen, M. S., Jones, M. V., \& Sheffield, D. (2009). Attribution, emotion, and collective efficacy in sports teams. Group Dynamics: Theory, Research, and Practice, 13(3), 205-217. http://doi.org/10.1037/a0015149

Barki, H., \& Hartwick, J. (2004). Conceptualizing the concept of interpersonal conflict. The International Journal of Conflict Management, 15(3), 216-244. http://doi.org/10.1108/eb022913

Boss, M., \& Kleinert, J. (2015). Explaining social contagion in sport applying Heider's balance theory: First experimental results. Psychology of Sport and Exercise, 16, 160-169. http://doi.org/10.1016/j.psychsport.2014.10.006

Carron, A. V., Brawley, L. R., Eys, M. A., Bray, S. R., Dorsch, K. D., Estabrooks, P., ... Terry, P. C. (2003). Do individual perceptions of group cohesion reflect shared beliefs?: An empirical analysis. Small Group Research, 34(4), 468-496. http://doi.org/10.1177/1046496403254274

Carron, A. V., Colman, M., Wheeler, J., \& Stevens, D. (2002). Cohesion and performance in sport: A meta analysis. Journal of Sport \& Exercise Psychology, 24(2), 168-188.

Carron, A. V., Shapcott, K. M., \& Martin, L. J. (2014). The relationship between team explanatory style and team success. International Journal of Sport and Exercise Psychology, 12(1), 1-9. http://doi.org/10.1080/1612197X.2014.853898

Carron, A. V., Widmeyer, W. N., \& Brawley, L. R. (1985). The development of an instrument to 

assess cohesion in sport teams: The Group Environment Questionnaire. Journal of Sport Psychology, 7(3), 244-266.

Coffee, P., Greenlees, I., \& Allen, M. S. (2015). The TRAMS: The Team-Referent Attributions Measure in Sport. Psychology of Sport and Exercise, 16, 150-159. http://doi.org/10.1016/j.psychsport.2014.10.009

Coffee, P., \& Rees, T. (2009). The main and interactive effects of immediate and reflective attributions upon subsequent self-efficacy. European Journal of Sport Science, 9(1), 41-52. http://doi.org/10.1080/17461390802594227

Coffee, P., Rees, T., \& Haslam, S. A. (2009). Bouncing back from failure: The interactive impact of perceived controllability and stability on self-efficacy beliefs and future task performance. Journal of Sports Sciences, 27(11), 1117-1124. http://doi.org/10.1080/02640410903030297

De Dreu, C. K. W., \& Weingart, L. R. (2003). Task versus relationship conflict, team performance, and team member satisfaction: A meta-analysis. The Journal of Applied Psychology, 88(4), 741-749. http://doi.org/10.5465/APBPP.2002.7516590

Dithurbide, L., Sullivan, P., \& Chow, G. M. (2009). Examining the influence of team-referent causal attributions and team performance on collective efficacy. Small Group Research, 40(5), 491-507. http://doi.org/10.1177/1046496409340328

Goncalo, J. A., \& Duguid, M. M. (2008). Hidden consequences of the group-serving bias: Causal attributions and the quality of group decision making. Organizational Behavior and Human Decision Processes, 107(2), 219-233. http://doi.org/10.1016/j.obhdp.2008.02.011

Hart, P. (1991). Irving L. Janis' victims of groupthink. Political Psychology, 12(2), 247-278. Retrieved from http://www.jstor.org/stable/3791464\%5Cn 
584 585

Heider, F. (1958). The psychology of interpersonal relations. New York: Wiley.

Jackson, B., Dimmock, J. A., Gucciardi, D. F., \& Grove, R. J. (2011). Personality traits and relationship perceptions in coach-athlete dyads: Do opposites really attract? Psychology of Sport and Exercise, 12(3), 222-230. http://doi.org/10.1016/j.psychsport.2010.11.005

Jehn, K. A. (1995). A multimethod examination of the benefits and detriments of intragroup conflict. Administrative Science Quarterly, 40(2), 256-282. http://doi.org/10.2307/2393638

Jehn, K. A., \& Mannix, E. A. (2001). The dynamic nature of conflict: A longitudinal study of intragroup conflict and group performance. Academy of Management Journal, 44(2), 238251.

Jonas, E., Schulz-Hardt, S., Frey, D., \& Thelen, N. (2001). Confirmation bias in sequential information search after preliminary decisions: An expansion of dissonance theoretical research on selective exposure to information. Journal of Personality and Social Psychology, 80(4), 557-571. http://doi.org/10.1037//0022-3514.80.4.557

Jones, E. E., \& Nisbett, R. (1971). The actor and the observer: Divergent perceptions of the causes of behavior. Attribution: Perceiving the Causes of Behavior. http://doi.org/10.1037//0022-3514.71.2.375

Kelley, H. (1967). Attribution theory in social psychology. Nebraska Symposium on Motivation.

Le Foll, D., Rascle, O., \& Higgins, N. C. (2008). Attributional feedback-induced changes in functional and dysfunctional attributions, expectations of success, hopefulness, and shortterm persistence in a novel sport. Psychology of Sport and Exercise, 9(2), 77-101. http://doi.org/10.1016/j.psychsport.2007.01.004

Mach, M., Dolan, S., \& Tzafrir, S. (2010). The differential effect of team members' trust on team performance: The mediation role of team cohesion. Journal of Occupational and 
Organizational Psychology, 83(3), 771-794. http://doi.org/10.1348/096317909X473903

Mitchell, D. E. (2018). Causes of organisational conflict. In Global Encyclopedia of Public Administration, Public Policy, and Governance (pp. 688-691). http://doi.org/10.2307/1246994

Moreland, R. L. (2010). Are dyads really groups? Small Group Research, 41(2), 251-267. http://doi.org/10.1177/1046496409358618

Paradis, K. F., Carron, A. V., \& Martin, L. J. (2014). Athlete perceptions of intra-group conflict in sport teams. Sport \& Exercise Psychology Review, 10(13), 4-18.

Pescosolido, A. T., \& Saavedra, R. (2012). Cohesion and sports teams: A review. Small Group Research, 43(6), 744-758. http://doi.org/10.1177/1046496412465020

Postmes, T., Haslam, S. A., \& Jans, L. (2013). A single-item measure of social identification: reliability, validity, and utility. The British Journal of Social Psychology / the British Psychological Society, 52(4), 597-617. http://doi.org/10.1111/bjso.12006

Postmes, T., Haslam, S. A., \& Swaab, R. I. (2005). Social influence in small groups: An interactive model of social identity formation. European Review of Social Psychology, 16, 1-42. http://doi.org/http://dx.doi.org/10.1080/10463280440000062

Rascle, O., Le Foll, D., Charrier, M., Higgins, N. C., Rees, T., \& Coffee, P. (2015). Durability and generalization of attribution-based feedback following failure: Effects on expectations and behavioral persistence. Psychology of Sport and Exercise, 18, 68-74. http://doi.org/10.1016/j.psychsport.2015.01.003

Rees, T., Ingledew, D. K., \& Hardy, L. (2005). Attribution in sport psychology: Seeking congruence between theory, research and practice. Psychology of Sport and Exercise, 6(2), 189-204. http://doi.org/10.1016/j.psychsport.2003.10.008 
630

631

632

633

634

635

636

637

638

639

640

641

642

643

644

645

646

647

648

649

650

651

652

Rees, T., Salvatore, J., Coffee, P., Haslam, S. A., Sargent, A., \& Dobson, T. (2013). Reversing downward performance spirals. Journal of Experimental Social Psychology, 49(3), 400403. http://doi.org/10.1016/j.jesp.2012.12.013

Satterthwaite, F. E. (1946). An approximate distribution of estimates of variance components. Biometrics Bulletin, 2(6), 110-114.

Sullivan, L. M., \& Agostino, R. B. D. (1992). Robustness of the t Test Applied to Data Distorted from Normality by Floor Effects. Journal of Dental Research, 71(12), 1938-1943.

Swaab, R. I., Postmes, T., Neijens, P., Kiers, M. H., \& Dumay, A. C. M. (2002). Multiparty negotiation support: The role of visualization's influence on the development of shared mental models. Journal of Management Information Systems, 19(1), 129-150. http://doi.org/10.1080/07421222.2002.11045708

Tajfel, H. (1970). Experiments in intergroup discrimination. Scientific American, 223(5), 96102. http://doi.org/10.1038/scientificamerican1170-96

Tajfel, H. (1982). Social psychology of intergroup relations. In Annual Review of Psychology (Vol. 33, pp. 1-39). http://doi.org/http://dx.doi.org/10.1146/annurev.ps.33.020182.000245

van Woerkom, M., \& Sanders, K. (2010). The romance of learning from disagreement. The effect of cohesiveness and disagreement on knowledge sharing behavior and individual performance within teams. Journal of Business and Psychology, 25(1), 139-149. http://doi.org/10.1007/s10869-009-9136-y

Weiner, B. (1985). An attributional theory of achievement motivation and emotion. Psychological Review, 92(4), 548-573.

Williams, K. D. (2010). Dyads can be groups (and often are). Small Group Research, 41(2), 268-274. http://doi.org/10.1177/1046496409358619 
653 Table 1. Study 2 Descriptive Statistics and Bivariate Correlations

\begin{tabular}{|c|c|c|c|c|c|c|c|}
\hline \multirow[b]{2}{*}{$\begin{array}{l}\text { Dependent } \\
\text { Variable }\end{array}$} & \multirow[b]{2}{*}{ Consensus } & \multirow[b]{2}{*}{$M$} & \multirow[b]{2}{*}{$S D$} & \multicolumn{4}{|c|}{ Bivariate Correlations } \\
\hline & & & & 1 & 2 & 3 & 4 \\
\hline \multirow{2}{*}{ 1. Conflict } & High & 1.29 & .53 & & & & \\
\hline & Low & 1.89 & .99 & & & & \\
\hline \multirow{2}{*}{ 2. Cohesion } & High & 3.07 & 1.18 & \multirow{2}{*}{-.26} & & & \\
\hline & Low & 2.54 & .58 & & & & \\
\hline \multirow{2}{*}{ 3. Social Identity } & High & 4.36 & 1.34 & \multirow{2}{*}{$-.27 *$} & \multirow{2}{*}{$.61 * *$} & & \\
\hline & Low & 3.43 & 1.10 & & & & \\
\hline \multirow{4}{*}{ 4. Performance 1} & High/Adaptive & 29.21 & 10.01 & \multirow{4}{*}{-.10} & \multirow{4}{*}{.22} & \multirow{4}{*}{.19} & \\
\hline & Low/Adaptive & 32.43 & 7.51 & & & & \\
\hline & High/Maladaptive & 29.78 & 8.27 & & & & \\
\hline & Low/Maladaptive & 28.28 & 11.38 & & & & \\
\hline \multirow{4}{*}{ 5. Performance 2} & High/Adaptive & 32.21 & 9.04 & \multirow{4}{*}{-.15} & \multirow{4}{*}{.20} & \multirow{4}{*}{.24} & \multirow{4}{*}{$.71 * *$} \\
\hline & Low/Adaptive & 30.79 & 9.19 & & & & \\
\hline & High/Maladaptive & 33.14 & 8.95 & & & & \\
\hline & Low/Maladaptive & 28.35 & 10.55 & & & & \\
\hline
\end{tabular}

654 Note. $\mathrm{M}=$ Mean, $\mathrm{SD}=$ Standard Deviation, ${ }^{*} \mathrm{p}<.05, * * \mathrm{p}<.01$.

655

656

657 